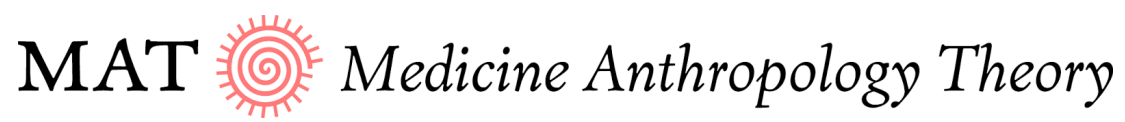

ARTICLE

\section{Diabetes, alcohol abuse, and inequality in southern Mexico A synergistic interaction}

Laura Montesi

\begin{abstract}
Despite the serious persistence of infectious diseases, low-income, indigenous people in southern Mexico are increasingly burdened by noncommunicable diseases, type 2 diabetes in particular. Most studies on diabetes and indigenous peoples focus on the dietary transition they are experiencing, with an emphasis on the biological role of processed foods and soft drinks on the onset of this disease. Little, however, is known about the synergistic interaction of alcohol abuse, diabetes, and inequality. This article adopts a syndemic approach to investigate how alcohol abuse among women and men in a rural, indigenous community in southern Mexico contributes to exacerbating health outcomes. Based on a one-year qualitative ethnographic study, this article advocates the use of a syndemic approach into the study of noncommunicable diseases because it offers critical insights into political economy, individual and social suffering, and the biosocial nature of health and illness.
\end{abstract}

\section{Keywords}

diabetes, alcohol abuse, syndemics, Mexico 


\section{Introduction}

Anita was sitting alone in the courtyard and feeding corn to the little chicks she kept in a box. Despite medical advice to wear shoes in order to avoid blisters and cuts, Anita's feet were bare because she said going barefoot gave her a sense of freedom. Her eyes were half closed and she looked visibly tired; she had gone through several surgeries in an attempt to save her eyesight, damaged by diabetes. That early afternoon, while we were talking, I asked her what she thought was the cause of her diabetes. She did not hesitate in answering:

I think it was susto [fright]. My husband started drinking a lot when we got married. He'd come home completely drunk. He seemed crazy, he first picked up a machete, and then a chair [to hit us]. You can't imagine. I didn't know what to do, my children were little, I got angry, he gave me muina [repressed anger] - why did he do that? . . . That's how I lived, that's how I raised my children. . . . But all of this was accumulating in me, surely all of this was accumulating in me, and it ended up becoming diabetes.

At the time of my fieldwork (2013-14), Anita, an Ikojts woman from southern Mexico, was fifty-five years old and had lived with diabetes for eighteen years. The events she recalled were part of her past. Her husband had lost the habit of beating her, yet the memories were still vivid when I first met her, and she linked her diabetes to spousal abuse unleashed by alcohol intoxication. Her words were not uncommon in San Dionisio del Mar, the rural village in southern Mexico where she lives. During my year of ethnographic research on the lived experiences and social representations of diabetes in this indigenous community, alcohol abuse ${ }^{1}$ and interpersonal violence were not isolated happenings. Diabetes narratives often disclosed stories of physical and emotional maltreatment interwoven with the emotional injuries of structural violence' (Singer 2009, 152), tangible in poverty, early deaths, wearing illnesses, precarity, and migration. Alcohol abuse cut across several of these stories, suggesting a synergistic interaction with type 2 diabetes (henceforth 'diabetes').

That diabetes serves as an idiom of distress through which people from underprivileged groups can speak about their living conditions and express their suffering has been demonstrated in a large body of anthropological literature. Rock $(2003,158)$ maintains that a focus on social suffering - suffering that 'results from what political, economic, and institutional power does to people' (Kleinman et al. 1997, ix) - is a promising hermeneutic

${ }^{1}$ By 'alcohol abuse' I mean a pattern of ethanol consumption that is harmful. Harm can be physiological, mental (psychological), and social (physical, emotional, economic). Harm can be directed at oneself and/or at others. 
approach to studying diabetes and health disparities. By exploring diabetes narratives, some authors have unveiled the durable bidirectional relationship between chronic stress due to disadvantaged life circumstances and diabetes (Cabassa et al. 2008; Ferreira and Lang 2006; Mendenhall et al. 2010; Mendenhall et al. 2012; Mendenhall and Jacobs 2012; Scheder 1988, 2006; Schoenberg et al. 2005; Thapa 2014). These works show the entanglement of biology and social conditions.

Drawing on medical anthropology literature that examines 'interaction and recursivity' (Manderson and Warren 2016, 482) between health conditions, in this article I consider adverse interactions among social inequality, diabetes, and alcohol abuse in Mexico, with a focus on rural indigenous people. While literature on food transitions and Western acculturation (see Ferzacca 2012 for a review) abounds, little has been written about the link between legal drugs and diabetes, despite scientific evidence indicating that smoking (Eliasson 2003; Foy et al. 2005) and drinking (Baliunas et al. 2009) can play a significant role in diabetes morbidity and mortality. Although drinking is often viewed from a 'lifestyle' perspective that disregards the workings of power on individual and collective lives, I seek to explore biosocial interconnections within a political economy framework. To do so, I employ syndemic theory, which is ideal for analysing the nexus of biology (diabetes), social inequality (a historical disadvantage), and a condition (recurrent alcohol abuse) that intersects all three domains.

In order to show this, the article moves from the macro to the micro. First, I provide a short introduction to the public health panorama in Mexico and argue why syndemic theory is particularly suitable for the study of diabetes and alcohol abuse. This is followed by a description of methods used, after which I dedicate a section to describing the legacies of colonialism in the social life of alcohol among Sandionisians. I then present and discuss case studies that show how important alcohol is in the history of the diabetes syndemic among some of these rural indigenous families. I close by suggesting that alcohol abuse should be considered a cofactor in the aetiology of diabetes in contexts where social histories are burdensome and inequalities enduring.

\section{Diabetes and alcohol abuse in Mexico: Why a syndemic?}

The term 'syndemic' was introduced by anthropologist Merrill Singer in the mid-1990s as a theoretical tool within the field of critical medical anthropology. It enhances our capacity to analyse disease not as a single biological entity (Singer and Clair 2003) but as a dynamic biosocial phenomenon that interacts synergistically with other disorders. Three main features make up the syndemics concept: 'the clustering of two or more diseases within a population; the biological, social, and psychological interaction of those diseases; and the large-scale 
social forces that precipitate disease clustering in the first place' (Mendenhall 2017, 889). The theory converges with social epidemiology approaches that focus on health disparities and assume a population perspective. Unlike social epidemiology, however, syndemic theory maintains an interest in individual life experiences and biosocial trajectories, revealing how macro-level forces inscribe themselves in individual bodies.

While, at first, syndemic theory was applied particularly to infectious diseases, HIV/AIDS foremost (Singer 1996; Bulled and Singer 2011), more recently there has been a growing interest in noninfectious health issues. For instance, Everett and Wieland (2013) have used syndemics to analyse the interactions among stunting, metabolic syndrome, and political economy in Oaxaca, demonstrating that food deprivation has long-lasting, intergenerational health consequences. Particularly useful to the study of alcohol abuse, diabetes, and inequality is the concept of 'syndemic suffering', which Mendenhall (2012) uses to investigate the syndemic clustering of violence, immigration-related stress, diabetes, depression, and abuse (VIDDA), among immigrant Mexican women in the United States. Syndemic suffering, in fact, stresses the experiential level and focuses on the phenomenology of affliction, never losing sight of the social forces shaping individual life experiences. Men, especially, use alcohol to deal with negative emotions and socially driven frustrations (Singer et al. 1992; Pérez 2000), prompting the reading of alcohol abuse as a form of self-medication of emotional problems that is shaped by structural violence (Singer 2009, 152).

The abusive drinking-diabetes syndemic (ADD) involves multiple, sometimes overlapping layers of vulnerability that 'dispose individuals toward taking actions and adopting ways of being that frequently result in endangering or placing their social and health status at risk' (Quesada 2011, 389). The analysis of the ADD syndemic in Mexico brings us to consider the wounding effects that social history has had on indigenous populations in at least three aspects. First, colonialism had irrevocable implications in subjugating some groups and elevating others along lines of ethnicity and class. The most deeply affected were the indigenous populations, which is apparent from their present social, health, and financial problems. According to recent data, 79.3 per cent of the indigenous speakers in Mexico live in poverty or extreme poverty, and more than 80 per cent have no social health insurance (Juárez-Ramírez et al. 2014, 285) due to their exclusion from formal economic activities, upon which medical coverage in the Mexican health care system largely depends. Furthermore, the principal causes of death among elderly indigenous people are chronic conditions such as diabetes and undernourishment (Juárez-Ramírez et al. 2014, 285), evidence of the coexistence of 'new' and 'old' maladies. Second, in Mexico, more than 13 per 
cent of adults present alcohol dependence syndrome ${ }^{2}$ (CDI 2008, 10) and, according to the National Commission for the Development of Indigenous Peoples, alcohol abuse is implicated in five of the first ten causes of death among rural Mexicans, a population that has a significant indigenous component (CDI 2008, 12). Ethnographic works also demonstrate high rates of alcohol dependence in rural communities (Romanucci-Ross 1973; Kearney 1972, 96-109) and strong linkages between alcohol abuse and interpersonal violence (Lerin and Ríos 2007, 762). Despite this, public health actions on alcohol abuse in rural Mexico are still as 'scant and discontinuous' as Menéndez (1990, 32-33) documented almost thirty years ago. Third, the above-mentioned structural vulnerabilities set the premises for substance abuse, especially among men, and interpersonal violence, particularly but not exclusively male-to-female physical violence. The ADD syndemic, therefore, has a profoundly gendered dimension that needs to be explored by articulating emic and etic perspectives, namely taking into consideration what aspects of their stories women and men find meaningful in relation to their diabetes and what 'antecedent and present factors and forces' (Quesada 2011, 389) end up shaping both the adverse circumstances they live in and the kinds of gendered responses available to women and men.

A large body of anthropological research has explored life stories of people with diabetes, revealing that diabetes intersects with experiences of race- and class-based discrimination (Thapa 2014), gender violence (Montesi 2017), and immigration status discrimination (Mendenhall 2012), which are often actualised in verbal, emotional, physical, and sexual abuse. Analysing stories of diabetes, authors have often documented alcohol abuse as an important social stressor affecting the physical and emotional health of people with diabetes. For example, Mendenhall and colleagues (2015) in their study of poor people in urban Kenya identified that living with an alcoholic family member was a source of stress among people with diabetes, particularly women. However, few studies have been specifically designed to investigate how alcohol interacts biologically, socially, and psychologically with diabetes in contexts of social deprivation. This article is an invitation to focus on the role alcohol abuse plays in the diabetes epidemics among colonised populations. Given the diabetes prevalence in Mexico (14.7 per cent vs. world prevalence 8.8 per cent, and the highest in Latin America; IDF 2015) and the weight of alcohol dependence syndrome among Mexican families, Mexico offers a pivotal case for such an endeavour.

${ }^{2}$ The WHO (n.d.) defines dependence as 'the state of needing or depending on something or someone for support or to function or survive', and dependence syndrome as 'a cluster of behavioural, cognitive, and physiological phenomena that may develop after repeated substance use'. Alcohol abuse is different from alcohol dependence but it can be a prelude to its development. This is why information on alcohol dependence is here considered insightful and included. 
Diabetes, alcohol abuse, and inequality

\section{Methods}

This article is based on data I collected in San Dionisio del Mar, Oaxaca, between September 2013 and August 2014, and draws on the same research as Montesi 2017. Due to privacy concerns, I use pseudonyms and disguise participants' identities. Even though most of this research derives from these twelve months of intensive fieldwork, my understanding of local drinking patterns stems from long-term participant observation and intermittent stays in the community over a period spanning from 2009 to the present. The study I conducted in 2010 on ritual Catholic life and people's conversions to evangelical Protestantism (Montesi 2012) allowed me to identify the local values attached to alcohol consumption and the moral economy sustaining it.

As part of my larger study on diabetes, I interviewed thirty-eight people with self-reported diabetes, both women and men (twenty-six and twelve, respectively), about what they thought were the particular causes of their diabetes and of diabetes more generally, how they first discovered that something was wrong, how their condition had developed, how they managed their diabetes, what their feelings and sensations (including symptoms) were, what therapists they had sought help from, if they were affiliated with Oportunidades (a conditional cash-transfer programme), what their strongest fear in relation to diabetes was, and what their everyday strategies for feeling better were. The interviews ranged from fourteen minutes to two hours, with most lasting around one hour. Interviewees ranged in age from twenty-four to seventy-nine years, with a mean age of 56.7. The number of years they had lived with diabetes was 12.6 in average, with a range of one to thirty. All the women were married or widowed mothers and defined themselves as amas de casa (homemakers). Three of them also worked as seamstresses, one sold clothes, one was a traditional healer, and three managed their own grocery or tortilla shops. In all cases, their work activities were carried out at home; even the shops were part of their dwellings. All male participants were involved in agricultural activities to a certain degree but only five defined themselves as campesinos (peasant farmers). Of the others, two were teachers, one owned a pharmacy, two were lorry drivers, one was an intermediary selling crops, and one was a fish seller. Research participants spoke both Spanish and Umbeyajts, their native language. I conducted interviews in Spanish and, in two cases, in Umbeyajts, helped by a native-speaker research assistant. The role of alcohol in diabetes experiences emerged in the data analysis but was not asked about purposively. Alcohol as an indirect contributor to diabetes emerged explicitly in ten interviews. It was usually evoked in female participants' causation narratives as a stressor that caused or worsened their diabetes. As I have explained elsewhere (Montesi 2017), emotional distress was key in diabetes narratives. Four in five respondents related their diabetes to a powerful emotion - prevalently susto (fright), muina (repressed anger), and coraje (anger) - resulting from problematic life circumstances. I also interviewed four doctors, and spoke with a local pharmacist, a nurse, and four traditional healers. As part of my 
broader ethnographic engagement with Sandionisians with diabetes, I spent long periods of time with a few sick people and their families, accompanying them to the doctor and sharing meals and everyday chores from early morning to night. For a couple of months in 2014, I observed patient-doctor interactions in the local rural clinic.

\section{Alcoholisation and the legacies of colonialism}

San Dionisio del Mar is an indigenous Huave/Ikojts settlement on the Isthmus of

Tehuantepec. Like their fellow Isthmians, Ikojts find themselves trapped in the contradictions of their region, which is economically strategic and attracts multimillion-dollar foreign investments while the benefits reach only a few. In San Dionisio, 85.9 per cent live in poverty and only 1.3 per cent are not poor or vulnerable (CONEVAL 2010). On the isthmus, alcohol consumption and intoxication are particularly intense and recurrent, a feature documented by several anthropological works on the region (Bresciani 2012; Chiñas 1992; Lerin and Miano Borruso 2009; Miano Borruso 2002; Montesi 2012).

Indeed, historians and anthropologists have long demonstrated that alcohol, similarly to other prestigious commodities such as tea, sugar, tobacco, and caffeine, has played a key role in the development of capitalism in modern times. They usually agree upon the fact that colonialism profoundly altered how alcohol was produced, exchanged, and consumed. The commercialisation of alcohol during colonial times secularised drinking, multiplied the number of taverns, and contributed to the rise of a new entrepreneurial class, thereby heightening social stratification within communities (Taylor 1979, 38). Moreover, as Winkelman and Bletzer (2005, 347) write: 'Modernisation made drugs widely available, enabling the development of the concept of addiction and processes of dependence'. Alcohol therefore became an instrument of dominance in the hands of those who controlled the means of production and distribution, and who were in the position of condemning intoxication within subordinate populations, thus legitimising the subjugation of these populations on moral grounds (Earle 2008).

The strong link between capitalism and alcohol is evident when looking at the recent cultural history of alcohol consumption in San Dionisio del Mar. This is a village of fishermen and peasant farmers who began to experience out-migration following a decline in the viability of traditional activities and a lack of job opportunities. Today, there are around thirty cantinas (bars) in the village, for a total population of 3,140. Alcohol sales represent an important source of revenue for the municipal government through taxation. For the families owning small groceries or cantinas, selling alcohol can be quite profitable, something of undeniable importance in a community where so much of its population lives in poverty and only a small minority has a regular work contract. 
The first anthropologist to grasp the importance of alcohol in the Sandionisian socioeconomic and political life was Hans R. Frey, who in the 1980s documented the increase in alcohol consumption and the key role that this commodity played in determining relations of authority both within the community and between the community and the broader regional market system. While studying the secularisation of political life in San Dionisio, Frey (1982a, 1982b) analysed the intensification of state interventions in the local economy and the parallel alteration of moral and religious life. According to him, the period between the 1950s and the 1970s was crucial in bringing about major modifications in Sandionisian social relations of production. Through credit investments and the technification of fishing, the state accelerated the integration of peasants/fishermen into the capitalist economy. The 1970s saw a sharp increase in production and an unprecedented flow of cash to the community. According to Bresciani (2012, 70-80), who analysed patterns of alcohol consumption and distribution in San Dionisio from a critical perspective, the sale of alcohol flourished alongside the booming fishing activity and in a relatively short period of time the community entered an 'alcoholisation' process, 'which is related to the politicaleconomy and ideological conditions that determine: the "massive" consumption of alcohol; the emergence of "alcoholism" as a medical problem and an issue of social control; [and] the construction of a "curative" and preventive model that shows its permanent inefficacy" (Menéndez et al. 1984, 439; my translation).

In the long run, the local consolidation of capitalist social relations increased Sandionisians' dependence on financial capital and worsened their social position. Despite the initial positive results, the costs associated with operating and maintaining the fishermen's equipment and with other investments were high (Frey 1982b, 50-54). Moreover, the market was monopolised by Zapotecs and mestizos (the dominant ethnic groups in the region), who also controlled oil, roads, and public transport. Eventually, the environmentally irrational exploitation of the fish stocks in the lagoons put an end to their seemingly limitless abundance, causing the Ikojts to suffer a decrease of food as well as their economic and political sovereignty (Cuturi 1990). As a result, migration started to become an important phenomenon in San Dionisio in the early 1990s. This overall process was accompanied by increased social stratification, further dependence on money, new forms of poverty, and shifting patterns of prestige.

In the collective memory of the Ikojts, the macro-level processes described above have local names and faces. The entrepreneurial activities that made some people a lot of money involved the commercialisation of objects that came from outside and were associated with wealth. In San Dionisio, the first 'rich' people were not Ikojts but Zapotecs who settled there between the 1940s and the 1950s and worked as intermediaries, selling the peasants' sesame harvest to neighbouring Zapotec centres. They also lent money and sold staples such as sugar and coffee, but it was the monopoly they enjoyed over the sale of alcohol that 
cemented their fortune (Toledo 2013, 294-307). Thanks to the two families that monopolised the sale of the beer brands Corona and Carta Blanca, the brewing industry entered the community, changing drinking patterns profoundly. Beer quickly began to pervade local customs, largely replacing more traditional drinks such as coyol wine, produced in the neighbouring area of Ixhuatán, Oaxaca. In 1981 the mayordomos of the patron saint, for the first time, made a deal with Corona for their sponsorship of the mayordomia celebration (Frey 1982a, 60). Since then, three main drinking patterns - festive, ritual, and in the cantinas - developed and are visible today (Bresciani 2012). Bresciani defines the first pattern as a sort of 'social alcoholism': during life-stage and religious celebrations, all women and men are expected to drink to the point of inebriation and often continually for two or more days. People perceive this drinking behaviour ambivalently. Though cherished as a demonstration of friendship and comradeship, it is also a cause for concern since drunkenness often results in fights and episodes of domestic violence. The second drinking pattern, linked to traditional rituals (such as the petition for rain), follows ancient drinking rules: only adult men can share alcohol, usually mezcal. Finally, drinking in cantinas is socially disapproved of and judged as a form of deviance.

It is also worth stating that emic views on alcohol today vary widely especially due to the presence of evangelical and Pentecostal groups that began to make inroads into the community in the 1940s. Promoting absolute abstinence, they have been able to attract at least 14 per cent of the population. Religious conversion seems to be the only institutional pathway available to Sandionisians for detoxification.

Overall, it can be said that the alcoholisation process, which many Ikojts families are experiencing, is strongly linked to their unequal participation in the market system and the transfer of wealth from the community to dominant sectors of society. It is a political economic history within which alcohol abuse, violence, and diabetes are inextricably connected.

\section{Heavy episodic drinking and diabetes: An overlooked relationship}

Studies on alcohol consumption and diabetes, albeit still with mixed results, suggest the existence of a connection. Alcohol consumption might be related to diabetes through its effects on insulin secretion and sensitivity (Facchini, Chen, and Reaven 1994; McMonagle and Felig 1975). Most studies have found a statistical association between alcohol consumption and the risk of developing diabetes (Carlsson, Hammar, and Grill 2005), with low-to-moderate consumption showing less risk of developing diabetes compared to either abstinence or high consumption (Pietraszek, Gregersen, and Hermansen 2009, 367). Binge 
drinking, or heavy episodic drinking, has been shown to be particularly detrimental (BodenAlbala and Sacco 2000; Fleming et al. 1999).

In San Dionisio, the alcohol-diabetes relationship is barely recognised by Sandionisians and health care workers. This means that community-based care is not prepared to address how heavy drinking contributes to the worsening of diabetes outcomes. Sandionisians with diabetes, who are encouraged to avoid sweet foods and beverages, say that the bitterness of beer makes drinking it safe. Eating or drinking bitter or salty food and beverages is sometimes believed to counterbalance the 'sweetness' of the blood, and I met people with diabetes who had drunk seawater or eaten large quantities of dried, salty shrimp to solve their problem.

The main way that Sandionisians acknowledge a causative influence of alcohol, beer in particular, on diabetes is through the interaction of hot and cold, as a part of the hot/cold humoral system. On several occasions, I heard people linking diabetes, which is locally conceptualised as hot, to exposure to cold drinks. Older people often mentioned that diabetes was rare when there was no electricity and beer was drunk al tiempo (at room temperature), not refrigerated. Concern about the role of cold drinks, including beer, in diabetes development was even brought up during medical visits, as this doctor-patient interaction (28 April 2014) illustrates:

Doctor: Any doubts or questions? Something more I can do for you?

Patient: Well, one question. If I drink cold, I mean, have a drink, can I use ice or is it harmful?

Doctor: Ice in itself isn't harmful. The issue here is that all the drinks we have with ice contain lots of sugar, so...

Patient: Simple water?

Doctor: Oh, that's ok, and there's no problem with the ice.

Patient: Some people say that it's not good to drink cold. Mine was just a question.

Doctor: There's no real problem with ice or cold as such. Ok?

Nutritional therapy at the clinic is centred on modifying the intake of food and soft drinks, and any reference to alcohol consumption is uncommon. Explicitly asked about the correlation between diabetes and alcohol consumption, the doctors I interviewed during 
follow-up research said they did not see any link between the two (23 August 2016). They recognised, however, that drinking alcohol hampers patients' adherence to diabetes treatment, an important acknowledgement since the ADD syndemic includes behavioural pathways. The fact that drinking alcohol affects diabetes self-management and interacts with hypoglycaemic agents prescribed to diabetics is well documented (Babor et al. 2012,152).

Sandionisians with diabetes admit to suspending their pharmacological treatment during celebrations. For example, Rogelio (forty-nine, diabetic for sixteen years) told me: 'When I drink, I don't take my pills and then, when I stop drinking and sober up, two or three days later, I take my medication again. This happens fairly often'. His words demonstrate that people with diabetes somehow sense that alcohol inhibits the efficacy of diabetes medication.

Overall, the patients I worked with showed great flexibility and independence in their medical treatment. They based their dietary and pharmacological intake both on their feelings and on traditional conceptualisations of health. This is well illustrated by Miriam, seventy-one and diabetic for twenty-one years, who said: 'Doctor says [I should take] three pills but I only take one. If there's a soft drink, I drink it. If there are two beers, I drink them too. I also need to eat bread in the morning and at night. ... I eat everything, just not what's in the fridge'. For the patients, the hot/cold food categorisation system overrides the doctor's dietary recommendations. This is just one of the several discrepancies I found between lay and medical understandings of diabetes. In sum, biological pathways linking alcohol and diabetes were largely unknown locally, while behavioural pathways, in this case the negative effects of alcohol consumption on the efficacy of pharmacological treatment, appear to be understood. However, the most prominent way that alcohol was associated with diabetes was as a stressor. Given its connections with precarity, financial pressures, and domestic violence, alcohol abuse could manifest as a precipitating or an exacerbating factor, which leads us now to explore the gendered dimension of the ADD syndemic.

\section{Living with an alcoholic family member: The emotional injuries of women with diabetes}

Three-quarters of the sample in my study identified an emotional injury - such as susto (fright), muina (repressed anger), coraje (anger), or mucho pensar (thinking too much) - as a direct cause of diabetes. Their emotional injuries were social in nature: family conflict over economic pressures; grief for family members injured or killed by enemies; sadness and despair for family members' illnesses and deaths, made worse by poverty; and interpersonal violence in the domestic sphere, especially intimate partner violence. Such stressful conditions were at the centre of most diabetes narratives. Alcohol abuse played a role in ten 
cases, as an intensifying factor. However, signalling alcohol as a direct contributor to emotional and physical violence and, in turn, as an indirect contributor to diabetes was a clearly gendered aetiological account, as eight of these ten accounts came from women.

Anita, the woman I introduced at the beginning of this article, presented a complex medical condition. Her diabetes was advanced: she had lost sensitivity in her fingers and lower extremities, her eyesight was highly impaired, her glucose levels continuously oscillated, and she had recurrent episodes of vomiting and diarrhoea. The way she described her life underlined a profound process of sense making in which past and present were interwoven. Anita, like most of the women I interviewed, emphasised that she was a hard-working woman, who, despite poverty, could provide for herself. She started working when she was five and learned to make tortillas, a highly skilled activity much appreciated in women. She wasn't able to go to school but learning how to make tortillas and then bread made her a resourceful woman. Getting married significantly changed her life, tying her to a man who abused her brutally. At one point, when her children were small, Anita considered leaving her husband but her mother discouraged her since a woman's status depends on her being married. As another woman with diabetes put it: 'When a woman leaves her husband, she is not respected anymore and neither are her children. Children need a father if you want them to be respected'. This attitude resulted in Anita's socially coerced decision to stay in her marriage and, as she said, to endure, aguantar. The injuries she suffered for years are vividly incarnated in her diabetes, which she maintains was caused by the multiple sustos she suffered at home. The diabetes complications she is experiencing today have further affected her sense of self as a strong, hard-working woman for she is no longer able to make tortillas and bread. This situation has made her more dependent on her husband, who is now entirely the provider. Today she copes with both her memories of the past and with her present situation, characterised by the constant feeling of being a burden on her family. Out-ofpocket expenses for treating diabetes complications are unavoidable in a context, like the one here on the isthmus, where public hospitals are chronically understaffed, underresourced, and overburdened. As Anita's case highlights, diabetes does not constitute an isolated health issue; it is intertwined with other structural vulnerabilities, such as the poverty of an overwhelmingly indigenous region where access to health care is uncertain and deficient, and where widespread alcoholisation traps men and women in difficult life struggles. Women have the additional challenge of having to maintain their legitimacy and honour based on their status of being wives and mothers. This gendered disadvantage makes it difficult for women to escape situations of domestic violence exacerbated by alcohol abuse, a challenge that becomes increasingly difficult to face and that, over time, manifests in ill health.

Like Anita, other women linked their diabetes to the tension induced by living with an alcoholic family member. Yuriria, sixty-nine, diagnosed with diabetes eight years before, 
thought her diabetes was a result of the suffering that her son's drunkenness and violence produced in her family:

My son used to drink a lot and then beat his wife. I asked him: 'Why do you beat your woman? She's going to get sick, you'll have to find medicine for her'. He said: 'You mamá, shut up, you don't know why we argue'. I replied: 'As long as I live here, I won't allow you to beat someone's daughter'. Since I was still strong, I used to intervene, grab the arm holding the machete and take it out of his hand. I got so angry.

Yuriria's words describe not only her own story but also her fear that diabetes could be caused by abuse. She saw a nexus between her son's irresponsible drinking and the possibility of her daughter-in-law falling ill with diabetes. And this illness is thought of as a particularly worrisome one since, as she told me, diabetes 'has no cure' and depletes people's finances.

Another woman, Karla, sixty-eight, described how three years earlier she developed diabetes due to the stressful conditions of living with an alcoholic husband: 'I got diabetes after a fight I had with my husband. He came back home drunk at five in the morning; we argued, I got very angry, and after a couple of hours I was in the clinic for my check-up. Of course my sugar was found to be high! My body was unhappy'. Karla went on to describe her family situation in detail:

I am a hard-working woman. I prepare atole [a corn-based drink] every morning and make money from that. My husband delivers it house to house and brings home what we earned. But he is such an irresponsible man that sometimes he finishes the atole and spends all the money in the cantina. I look at the clock, it's $10 \mathrm{am}$ : if he's not back, he's in the cantina. He ends up passed out on the pavement. Then someone comes and tells me that he's sprawled out somewhere, unconscious. Such an embarrassment for me! It comes as no surprise if my son is a drunkard as well.

Karla's story demonstrates how alcohol abuse, compounded with gendered conflict over financial resources in a context of paucity, can be embedded in stories of diabetes. This interconnection intensifies as abusive drinking spreads intergenerationally. Karla's emotional injuries multiply as she has to deal not only with her husband's abusive drinking but her son's, too: 
[My son] wastes his money. His wife comes to me crying and saying she's going to take their two daughters and leave him. I implore her not to, I tell her that as long as I live I will protect and help her. I think that if she's still at home it's because of our bond, because I love her. My son sleeps in the cantina, with other women, and my daughter-in-law's anger makes her sick. 'Don't get angry', I tell her. 'Look at what bad shape I'm in after all the anger I've felt'.

Karla blames her lamentable health on these stressors. At present, her diabetes fluctuates with the vicissitudes of her son's family. In addition, worrying too much influences her ability to adhere to treatment: 'I think too much because of my son. You can't eat well when you witness fighting in your family. I want to keep calm and be normal but I just can't. I can't act bravely, I feel weak, deranged. I am unable to put up with it'. She finds it difficult to take care of her diabetes while feeling the need to protect her daughter-in-law and help her with the emotional injuries she bears. This complicated family situation leaves Karla feeling sad and even guilty at being unable to 'endure' or do anything to counterbalance the effects that sadness has on her diabetes. Elsewhere (Montesi 2017), I have written about how diabetes is an ambivalent idiom for women; it helps them to speak about the unspeakable while also fomenting their feelings of culpability, namely that they are to blame for both the violence and the diabetes they suffer.

Karla was also deeply worried about her future and possibly having to deal with diabetes complications that would require hospitalisation. She showed a profound distrust of public health institutions, saying that the government uses them to get rid of the poor: "The government itself wants to kill the sick'. Karla observed that those who enter the hospital usually leave it dead. Her feeling of being vulnerable to the government's homicidal plans against the poor demonstrates the weight of colonial history in this region.

Patterns of violence and alcohol abuse are common, and not all abused women can count on their mother-in-law's moral support. Sandra, fifty-eight, has been diabetic for sixteen years and lives with her husband, a white-collar worker. Compared to their fellow Sandionisians, they have a higher socioeconomic position and their four children have all completed secondary school. Sandra's story of diabetes interweaves sickness with alcohol abuse and intimate partner violence. As such, it presents similarities with the story of Anita. However, Sandra had an additional vulnerability: she came from a distant Oaxacan village and had left her family of origin to start her new life as a married woman. Sandra often recalled how difficult it was for her to get used to a new place, a different diet, another language, and customs she defined as 'backward'. Moreover, being a foreigner in this, as she called it, 'isolated' village made her more reliant on her husband. Although a woman's family of origin might discourage her from fleeing a violent marriage, as we have seen, it is also true that parents and siblings may offer protection in other ways, including mediating conflicts with 
the son-in-law and sheltering abused women. Living so far away and in what she considered isolation, Sandra found herself limited in her ability to deal with an alcoholic husband:

He was fine when he was sober. But when drunk, he became grosero [rough], he beat me. I was so scared, and my mother-in-law told me that it was my fault because I let him beat me. I was desperate and instead of getting angry with my husband, I got angry with my children. I wasn't used to this. My father didn't drink. When I arrived here, at my husband's home, his father used to drink for twenty or twenty-five days in a row, so awful! He beat my mother-in-law. I was frightened. I cried. These experiences change your life radically. Living with a drunkard is a lot of work.

Sandra's testimony illustrates the cycles of violence in her acquired family. She feels isolated and frustrated at being a victim of physical and emotional abuse while, at the same time, being blamed for her husband's conduct. Interestingly, her mother-in-law, a victim of domestic violence herself, blames Sandra instead of protecting her, fuelling Sandra's resentment. Unable to confront her husband, Sandra takes her resentment out on the children, thereby reproducing another cycle of violence. Like Anita, she communicates her discomfort through idiomatic expressions such as susto and coraje that she links to her diabetes.

These testimonies signal the causative and exacerbating power that inequalities have in diabetes stories. Inequality is visible in the financial struggles of these women and their families, and in their distrust in public health care, which is - when accessible - perceived to be deadly for the poor. Alcohol abuse disrupts family ties even when they are not formally broken. Alcohol has aggravating effects on violent behaviour against women, something of particular concern in Mexico, where gendered violence has tragic manifestations and proportions. Recent data (INEGI 2013, 8) indicate that 44.9 per cent of married women or women with a steady partner have suffered some form of violence from their partners at least once in their lives. In the last year, 51.2 per cent have been forced to have sexual relationships, 37.1 per cent have been attacked with a weapon, 48.0 per cent have been beaten, and 53.9 per cent have been confined to their homes or forbidden to see their acquaintances (INEGI 2013, 17). The direct and indirect effects of these forms of violence on women's well-being are difficult to assess fully. Illness narratives can be a starting point for such an exploration.

\section{Drinking as a male coping strategy}

The two men who mentioned alcohol in their illness narratives did so rather fleetingly, as part of what they described as their immoderate youth. All of the men with diabetes I 
interviewed shared the idea that diabetes was caused by strong emotions, unleashed by frightening episodes that had occurred outside the domestic sphere, either at work or on the streets. Even though men did not give much importance to alcohol when telling their diabetes stories, observation of their daily conduct and more general comments indicated that alcohol did play an important role in some of them. Rogelio, identified as a drunkard by his fellow Sandionisians, said that drinking alcohol was of great relief to him since it was cathartic and made him feel impervious to negative thoughts and sickness: 'Beer helps me clear my mind. It also makes me pee, cleansing everything. . . . When I don't drink sometimes I get a fever, sometimes a cough. But when I'm drinking nothing like this happens'. As I said earlier, drinking alcohol and getting intoxicated can be seen as a form of self-medication in a context where alcoholic beverages are perceived 'as idealized and unproblematic items of consumption' (Christensen 2012, 11) for men.

Alcohol abuse needs to be seen within both a cultural context that associates manliness with alcohol and an unequal socioeconomic context that inflicts emotional injuries on men while depriving them of opportunities to heal. According to Pérez (2000), alcohol and violence in rural Mexican communities act as vehicles for male frustrations over their loss of privilege as breadwinners and the growing autonomy of women. The absorption of San Dionisio into the capitalist market has led to a decline in traditional activities without providing men with alternative productive means, making out-migration one of the few possible hopes for a better life. Migratory experiences expose indigenous people to a plethora of dangers, and entry into the labour market is often marked by ethnic and class-based discrimination, reinforcing racialised hierarchies (Macip 2007).

As Singer $(2009,152)$ highlights, structural violence takes a great toll on human life and wellbeing due to 'some of the strategies people adopt in coping with the social suffering this violence inflicts. These strategies, including alcohol and drug abuse, obsessive gambling, and risky sexual behaviors, offer immediate relief but are ultimately self-destructive'. In a detailed account of why problem drinking must be analysed in terms of the conflictive dynamics produced within the larger political economic system, Singer and colleagues (1992) followed the steps of Juan, a Puerto Rican man who migrated to New York and died of alcoholrelated causes, whose case demonstrated a close link between unemployment and problem drinking. The story of José, a fifty-four-year-old lorry driver who had been living with diabetes for eighteen years, resonates with Juan's.

José had gone through a lot in his life, including the death of his daughter. When I interviewed him, he bore the signs of depression: fatigue, hopelessness, recurrent crying. His story of diabetes was one that centred on the loss of two of his five children and the lack of job opportunities. Talking about his diabetes, he said: 
Here there's poverty, I eat what falls on the table. ... I don't check my blood sugar, I keep it under control by staying calm. ... I think of my daughter when I stayed in the hospital with her, while she was incubated. I clean her, brush her hair, look at her, I feel horrible things. She suffered a lot. First an ulcer, then pneumonia, finally cancer. At first I couldn't work, I only cried. Now I'm a bit better. But there's no work. I want to work, sleep well. When I am working, I am fine, don't feel anything negative.

At one point, José commented on his aching feet, a result of his diabetes. I asked him if this was a problem given the long hours involved in driving a lorry. His answer was eloquent: 'When I am driving, I am working, then my body is perfectly fine. I smile, leave home [happy], and forget everything. But when I come back home and get into my hammock I start feeling bad. My thoughts go back to my daughter and my sugar gets altered particularly when I think I don't have enough work'.

For José, diabetes is no more burdensome than the memory of his child or his precarious working conditions. Anthropological literature indicates that in deprived social contexts, diabetes may not be perceived as a central concern. For example, among the Aborigine people studied by Bartlett and colleagues (2007, 2380), 'racism, abuse, loss, personal relationships, financial issues, and culture and spirituality are central themes'. People's real concerns influence their self-care behaviours. José says he does not take care of himself and suggests that in poverty there is no room for food choice.

During my stay in San Dionisio, I often saw José sitting alone in front of his house, his eyes listless. Other times I saw him in the cantina drinking in companionship until intoxicated. In our interview, he mentioned that his mood fluctuated and he cried often. Evidence also demonstrates a connection between alcohol abuse and depression. Although alcohol can be a form of self-medication, studies like those of Merikangas and Gelernter (Tann 2007, 4) indicate that depressive syndrome is more common among alcoholics than among nonalcoholics. Considering that depression is also bidirectionally associated with diabetes, we find here a complex synergistic interaction, typical of a syndemic.

As Weaver and Mendenhall $(2014,102)$ comment, 'syndemics theory allows us to examine the multiple layers of suffering experienced throughout the life course and to consider implications of such suffering on concurrent depression and diabetes'. José's story reveals these multiple layers of suffering: the experience of living under economic pressures, family members' early deaths, and precarious work conditions. This article, therefore, endorses the consideration of the interconnections among suffering, depression, and diabetes, as signalled by Weaver and Mendenhall, and encourages the inclusion of alcohol abuse in the analysis of 
the Mexican diabetes epidemic. This ADD syndemic could be at work in other regions and countries as well.

\section{Conclusions}

The life experiences portrayed in this article exemplify how alcohol abuse, through multiple causal pathways, increases the risk of diabetes for minority and impoverished people, and exacerbates the consequences of diabetes when acting in conjunction with suffering and interpersonal violence in contexts of profound inequality. Despite this complex scenario shaping diabetes experiences, public health discourses and standard medical interventions still tend to approach diabetes in individualised terms through a 'lifestyle' focus that emphasises the direct impact of diet on health and illness management.

More structural responses have also been adopted recently, for example the passage of a law imposing a tax on soft drinks. These kinds of measures may be helpful but are certainly not sufficient. They betray a one-dimensional understanding of diabetes, as if it were only a result of wrong behaviours on the part of 'consumers'.

Here I have argued that an analysis of abusive drinking reveals a great deal about political and economic structures affecting the health of poverty-stricken populations through multicausal biological, phenomenological, and social pathways. The stories of the women and men in this study reveal the weight that structural and ordinary violence has in the shaping of health inequalities and the rise of diabetes in middle-income countries. In particular, I have explored the synergistic interaction among alcohol abuse, interpersonal violence, and suffering among Mexico's rural indigenous people, who find themselves at the bottom of the social ladder.

More studies on ADD syndemics are needed and these should take into consideration gender, ethnicity, rural/urban status, and migration as factors influencing diabetes and alcohol incidence and prevalence rates. First, the diabetes epidemic needs to be explored through a syndemic approach, allowing researchers to identify the relationships among biosocial phenomena rooted in contexts characterised by disadvantage and historical inequality. Tackling the diabetes epidemic requires multiple and diverse synergistic interventions, which include implementing preventive measures against interpersonal violence, regulating alcohol sales, offering employment services, supporting rural economies, and promoting 'syndemic care'. Mendenhall and colleagues $(2015,18)$ define the latter as 'coordinated, patient-centered medical visits' that involve simultaneous diagnosis and treatment of multiple health issues. 
Second, since both alcohol abuse and diabetes often develop in association with the suffering intrinsic to life situations where poverty and uncertainty are an everyday reality, diabetes research and interventions would benefit from considering alcohol consumption more seriously. In Mexico alcohol abuse is a key concern in families living with diabetes since alcohol hampers diabetes treatment, worsens domestic tensions, and inflicts pain on family members.

Third, future studies on the ADD syndemic should include a gendered approach that explores how macroeconomic changes, such as the proletarianisation of men and women, alter gender relations and give rise to power conflicts between the sexes that can easily, in certain circumstances, be fuelled by alcohol abuse. The women in my sample reported that their male family members' abuse of alcohol led to physical and emotional violence at home, which in turn, they believed, contributed to the onset of their diabetes. Though the subject of alcohol was missing from men's narratives, in certain cases alcohol abuse was a way for men with diabetes to cope with dire circumstances. Further studies should explore men's and women's unique individual experiences and strategies for dealing with their emotional injuries. It is worth adding that women, too, are increasing their alcohol consumption and that episodes of female-to-male violence remain to be researched.

Fourth and finally, public health interventions should avoid medicalising alcohol abuse and focus instead on helping to develop dealcoholisation projects at the community level, promoting moderate drinking patterns, and addressing what is behind the massive consumption of industrially produced alcohol.

\section{Acknowledgements}

The research on which this article is based was funded by a University of Kent Scholarship, a scholarship from the Mexican government, and a Wenner-Gren Dissertation Fieldwork Grant (n.8884), while I was a doctoral student at the University of Kent, UK. An earlier draft of this article was presented in January 2017 at the Interdisciplinary Workshop on Critical Medical Anthropology led by Jennie Gamlin and Sahra Gibbon from University College London (UCL) and Lina Rosa Berrio and Paola Sesia from the Centre for Research and Higher Studies in Social Anthropology (CIESAS). Gratitude goes to the anonymous reviewers who helped me improve my manuscript, to my colleague Tony Knight, and to my editor, Christine Streit Guerrini. I am particularly indebted to the women and men who participated in this study for their generosity and willingness to share their stories. 


\section{About the author}

Laura Montesi is postdoctoral researcher at the Centre for Research and Higher Studies in Social Anthropology (CIESAS) in Oaxaca City.

\section{References}

Babor, Thomas, Jurgen Rehm, David Jernigan, Patrice Vaeth, Maristela Monteiro, and Hallie Lehman. 2012. 'Alcohol, Diabetes, and Public Health in the Americas'. Revista Panamericana de Salud Pública 32 (2): 151-55.

Baliunas, Dolly O., Benjamin J. Taylor, Hyacinth Irving, Michael Roerecke, Jayajeep Patra, Satya Mohapatra, and Jürgen Rehm. 2009. 'Alcohol as a Risk Factor for Type 2 Diabetes: A Systematic Review and Meta-Analysis’. Diabetes Care 32 (11): 2123-32.

Bartlett, Judith G., Yoshitaka Iwasaki, Benjamin Gottlieb, Darlene Hall, and Roger Mannell. 2007. 'Framework for Aboriginal-Guided Decolonizing Research Involving Métis and First Nations Persons with Diabetes'. Social Science and Medicine 65 (11): 2371-82. https://doi.org/10.1016/j.socscimed.2007.06.011.

Boden-Albala, Bernadette, and Ralph Sacco. 2000. 'Lifestyle Factors and Stroke Risk: Exercise, Alcohol, Diet, Obesity, Smoking, Drug Use, and Stress'. Current Arteriosclerosis Reports 2 (2): 160-6.

Bresciani, Chiara. 2012. 'Así salí del alcohol: Consumo di alcol, alcolismo e riscatto in una comunità indigena huave (Oaxaca, Messico)'. MA diss., University of Bologna.

Bulled, Nicola, and Merrill Singer. 2011. 'Syringe-Mediated Syndemics'. AIDS and Behavior 15 (7): 1539-45. https://doi.org/10.1007/s10461-009-9631-1.

Cabassa, Leopoldo, Marissa C. Hansen, Lawrence A. Palinkas, and Kathleen Ell. 2008.

'Azúcar y Nervios: Explanatory Models and Treatment Experiences of Hispanics with Diabetes and Depression'. Social Science and Medicine 66 (12): 2413-24. https://doi.org/10.1016/j.socscimed.2008.01.054.

Carlsson, S., N. Hammar, and V. Grill. 2005. 'Alcohol Consumption and Type 2 Diabetes: Meta-Analysis of Epidemiological Studies Indicates a U-Shaped Relationship’. Diabetologia 48 (6): 1051-54.

Chiñas, Beverly N. 1992. The Isthmus Zapotecs: A Matrifocal Culture of Mexico. 2nd ed. Fort Worth, TX: Harcourt Brace Jovanovich Publishers.

Christensen, Paul. 2012. 'Real Men Don't Hold Their Liquor: The Complexity of Drunkenness and Sobriety in a Tokyo Bar.' Social Science Japan Journal 15 (2): 239-54. https://doi.org/10.1093/ssij/jys005.

Comisión Nacional para el Desarrollo de los Pueblos Indígenas (CDI). 2008. Informe general de la consulta sobre alcoholismo y pueblo indígenas. Mexico City: CDI. 
Consejo Nacional de Evaluación de la Política de Desarrollo Social (CONEVAL). 2010. Indicadores de pobreza, pobreza por ingresos, gini y rezago social 1990/2000/2005/2010 a nivel municipal.

http://web.coneval.gob.mx/Informes/Pobreza/Datos_abiertos/Indicadores_muni cipales_sabana_DIC.txt.

Cuturi, Flavia. 1990. 'Dalla laguna delle Sirene al mercato dei gamberi'. La Ricerca Folklorica 21: 61-68.

Earle, Rebecca. 2008. "Algunos pensamientos sobre "El indio borracho" en el imaginario criollo'. Revista de Estudios Sociales 29: 18-27.

Eliasson, Björn. 2003. 'Cigarette Smoking and Diabetes'. Progress in Cardiovascular Diseases 45 (5): 405-13. https://doi.org/10.1053/pcad.2003.00103.

Everett, Margaret, and Josef N. Wieland. 2013. 'Diabetes among Oaxaca's Transnational Population: An Emerging Syndemic'. Annals of Anthropological Practice 36 (2): 295311. https://doi.org/10.1111/napa.12005.

Facchini, F., Y. D. Chen, and G.M. Reaven. 1994. 'Light-To-Moderate Alcohol Intake Is Associated with Enhanced Insulin Sensitivity'. Diabetes Care 17: 115-19.

Ferreira, Mariana K. L., and Gretchen C. Lang, eds. 2006. Indigenous Peoples and Diabetes: Community Empowerment and Wellness. Durham, NC: Carolina Academic Press.

Ferzacca, Steve. 2012. 'Diabetes and Culture'. Annual Review of Anthropology 41: 411-26. https://doi.org/10.1146/annurev-anthro-081309-145806.

Fleming, Michael, Linda Baier Manwell, Kristen Lawton Barry, Wendy Adams, and Ellyn Stauffacher. 1999. 'Brief Physician Advice for Alcohol Problems in Older Adults: A Randomized Community-Based Trial'. Journal of Family Practice 48 (5): 378-84.

Foy, Capri Gabrielle, Ronny A. Bell, Deborah F. Farmer, David C. Goff, Jr., and Lynne E. Wagenknecht. 2005. 'Smoking and Incidence of Diabetes among U.S. Adults: Findings from the Insulin Resistance Atherosclerosis Study'. Diabetes Care 28 (10): 2501-07. https://doi.org/10.1146/annurev-anthro-081309-145806.

Frey, Hans R. 1982a. La jerarquía político-eclesiástica y la mayordomia en San Dionisio del Mar, Oaxaca. Oaxaca, México: Universidad Autónoma Benito Juárez de Oaxaca.

Frey, Hans R. 1982b. Las actividades económicas y el desarrollo capitalista en San Dionisio del Mar, Oaxaca. Oaxaca, México: Universidad Autónoma Benito Juárez de Oaxaca.

Instituto Nacional de Estadística y Geografía (INEGI). 2013. Panorama de violencia contra las mujeres en los Estados Unidos Mexicanos (ENDIREH 2011). Aguascalientes, México: INEGI.

International Diabetes Federation (IDF). 2015. 'IDF Diabetes Atlas: 2015 Update'. http://www.oedg.at/pdf/1606_IDF_Atlas_2015_UK.pdf. Brussels: IDF.

Juárez-Ramírez, Clara, Margarita Márquez-Serrano, Nelly Salgado de Snyder, Blanca Estela Pelcastre-Villafuerte, María Guadalupe Ruelas-González, and Hortensia Reyes- 
Morales. 2014. 'La desigualdad en salud de grupos vulnerables de México: Adultos mayores, indígenas y migrantes'. Revista Panamericana de Salud Pública 35 (4): 284-90.

Kearney, Michael. 1972. The Winds of Ixtepeji: World View and Society in a Zapotec Town. Long Grove, IL: Waveland Press.

Kleinman, Arthur, Veena Das, and Margaret Lock, eds. 1997. Social Suffering. Berkeley: University of California Press.

Lerin, Sergio, and Marinella Miano Borruso. 2009. 'Mujeres y hombres bebiendo cerveza: Etnografía del consumo de alcohol en una comunidad zapoteca del Istmo de Tehuantepec'. Género y Salud en Cifras 7 (2): 26-35.

Lerin, Sergio, and Enrique Ríos. 2007. 'Salud mental y alcoholismo: Un tema intercultural olvidado. Propuesta de capacitación para el personal de salud que atiende a población indígena'. In Estudios de antropología biológica, edited by Magalí Civera Cerecedo and Martha Rebeca Herrera Bautista, 751-72. Mexico City: UNAM; IIA; INAH; AMAB.

Macip, Ricardo. 2007. 'Racismo y superexplotación: los jornaleros indígenas en el ejercito industrial de reserva'. Bajo el Volcán 7 (11): 45-60.

Manderson, Lenore, and Narelle Warren. 2016. “Just One Thing after Another”: Recursive Cascades and Chronic Conditions'. Medical Anthropology Quarterly 30 (4): 479-97. https://doi.org/10.1111/maq.12277.

McMonagle, J., and P. Felig. 1975. 'Effects of Ethanol Ingestion on Glucose Tolerance and Insulin Secretion in Normal and Diabetic Subjects'. Metabolism 24: 625-32.

Mendenhall, Emily. 2012. Syndemic Suffering: Social Distress, Depression, and Diabetes among Mexican Immigrant Women. London: Routledge.

Mendenhall, Emily. 2017. 'Syndemics: A New Path for Global Health Research'. Lancet 389: 889-91.

Mendenhall, Emily, Alicia Fernandez, Nancy Adler, and Elizabeth Jacobs. 2012. 'Susto, Coraje, and Abuse: Depression and Beliefs about Diabetes'. Culture, Medicine and Psychiatry 36 (3): 480-92.

Mendenhall, Emily, and Elizabeth Jacobs. 2012. 'Interpersonal Abuse and Depression among Mexican Immigrant Women with Type 2 Diabetes'. Culture, Medicine and Psychiatry 36 (1): 136-53. https://doi.org/10.1007/s11013-011-9240-0.

Mendenhall, Emily, Gregory Barnabas Omondi, Edna Bosire, Gitonga Isaiah, Abednego Musau, David Ndetei, and Victoria Mutiso. 2015. 'Stress, Diabetes, and Infection: Syndemic Suffering at an Urban Kenyan Hospital'. Social Science and Medicine 146: $11-$ 20. https://doi.org/10.1016/j.socscimed.2015.10.015.

Mendenhall, Emily, Seligman, Rebecca, Fernandez, Alicia, and Elizabeth Jacobs. 2010. 'Speaking Through Diabetes: Rethinking The Significance of Lay Discourses on Diabetes'. Medical Anthropology Quarterly 24 (2): 220-39. https://doi.org/10.1111/j.1548-1387.2010.01098.x. 
Menéndez, Eduardo. 1990. Morir de alcohol: Saber y hegemonía médica. Mexico City: Editorial Patria, Alianza Editorial Mexicana, Consejo Nacional para la Cultura y las Artes. Menéndez, Eduardo, Renée Di Pardo, Sergio Lerin, Sergio Navarrete, and Patricia Ravelo. 1984. 'El proceso de alcoholización en México'. In Anales 1983, edited by Marisol Schulz and Juan Rodríguez Yerena, 426-47. Mexico City: CIESAS.

Merikangas, K. R., and C. S. Gelernter. 1990. 'Co-Morbidity for Alcoholism and Depression'. Psychiatric Clinics of North America 13 (4): 613-32.

Miano Borruso, Marinella. 2002. Hombre, mujer y muxe' en el Istmo de Tehuantepec. Mexico City, Mexico: INAH and Plaza y Valdés.

Montesi, Laura. 2012. 'La costumbre y el Evangelio: Estrategias múltiples de transformación religiosa entre los huaves de Oaxaca (México)'. Virajes 14 (2): 277-97.

Montesi, Laura. 2017. “Como si nada”: Enduring Violence and Diabetes among Rural Women in Southern Mexico'. Medical Anthropology 14: 1-15. https://doi.org/10.1080/01459740.2017.1313253.

Pérez, Ramona L. 2000. 'Fiesta as Tradition, Fiesta as Change: Ritual, Alcohol and Violence in a Mexican Community'. Addiction 95 (3): 365-73.

Pietraszek, A., S. Gregersen, and K. Hermansen. 2009. 'Alcohol and Type 2 Diabetes: A Review'. Nutrition, Metabolism and Cardiovascular Diseases 20: 366-75. https://doi.org/10.1016/j.numecd.2010.05.001.

Quesada, James. 2011. 'No Soy Welferero: Undocumented Latino Laborers in the Crosshairs of Legitimation Maneuvers'. Medical Anthropology 30 (4): 386-408. https://doi.org/10.1080/01459740.2011.576904.

Rock, Melanie. 2003. 'Sweet Blood and Social Suffering: Rethinking Cause-Effect Relationships in Diabetes, Distress, and Duress'. Medical Anthropology 22 (2): 131-74. https://doi.org/10.1080/01459740390203454.

Romanucci-Ross, Lola. 1973. Conflict, Violence and Mortality in a Mexican Village. Palo Alto, CA: National Press.

Scheder, Jo C. 1988. 'A Sickly-Sweet Harvest: Farmworker Diabetes and Social Equality'. Medical Anthropology Quarterly 2 (3): 251-77.

Scheder, Jo C. 2006. 'The Spirit's Cell: Reflections on Diabetes and Political Meaning'. In Indigenous Peoples and Diabetes: Community Empowerment and Wellness, edited by Mariana Leal Ferreira and Gretchen Chesley Lang, 335-56. Durham, NC: Carolina Academic Press.

Schoenberg, Nancy E., Elaine M. Drew, Eleanor Palo Stoller, and Cary Kart. 2005. 'Situating Stress: Lessons from Lay Discourses on Diabetes'. Medical Antbropology Quarterly 19 (2): 171-93.

Singer, Merrill. 1996. 'A Dose of Drugs, a Touch of Violence, a Case of AIDS: Conceptualizing the SAVA Syndemic'. Free Inquiry in Creative Sociology 24 (2): 99-110. 
Singer, Merrill. 2009. Introduction to Syndemics: A Critical Systems Approach to Public and Community Health. San Francisco, CA: Jossey-Bass.

Singer, Merrill, and Scott Clair. 2003. 'Syndemics and Public Health: Reconceptualizing Disease in Bio-Social Context'. Medical Anthropology Quarterly 17 (4): 423-41.

Singer, Merrill, Freddie Valentín, Hans Baer, and Jia Zhongke. 1992. 'Why Does Juan García Have a Drinking Problem? The Perspective of Critical Medical Anthropology'. Medical Anthropology 14 (1): 77-108. https://doi.org/10.1080/01459740.1992.9966067.

Tann, Sheila, Scott Yabiku, Scott Okamoto, and Jessica Yanow. 2007. 'TriADD: The Risk for Alcohol Abuse, Depression, and Diabetes Multimorbidity in the American Indian and Alaska Native Population'. American Indian and Alaska Native Mental Health Research 14 (1): 1-23.

Taylor, William. 1979. Drinking, Homicide and Rebellion in Colonial Mexican Villages. Stanford, CA: Stanford University Press.

Thapa, Tirtha B. 2014. 'Living with Diabetes: Lay Narratives as Idioms of Distress among the Low-Caste Dalit of Nepal'. Medical Anthropology 33 (5): 428-40. https://doi.org/10.1080/01459740.2012.699985.

Toledo, Ezequiel Z. 2013. 'Configuración territorial y redes de poder: la interacción entre mareños y zapotecos en el oriente del istmo de Tehuantepec. El caso de San Dionisio del Mar (1910-1970)'. In Representando el pasado y el presente del istmo oaxaqueño: Perspectivas arqueológicas, históricas y antropológicas, edited by Laura Machuca and Judith Zeitlin, 287-307. Mexico City: CIESAS, University of Massachusetts Boston.

Weaver, Lesley Jo, and Emily Mendenhall. 2014. 'Applying Syndemics and Chronicity: Interpretations from Studies of Poverty, Depression, and Diabetes'. Medical Anthropology 33 (2): 92-108. https://doi.org/10.1080/01459740.2013.808637.

Winkelman, Michael, and Keith Bletzer. 2005. 'Drugs and Modernization'. In A Companion to Psychological Anthropology: Modernity and Psychocultural Change, edited by Conerly Casey and Robert Edgerton, 337-57. Malden, MA: Blackwell Publishing.

World Health Organisation (WHO). n.d. 'Lexicon of Alcohol and Drug Terms Published by the World Health Organisation'. http://www.who.int/substance_abuse/terminology/who_lexicon/en/. 